[Original Article]

Received February 27, 2017

Revised May 14, 2017

Accepted May 30, 2017

${ }^{\dagger}$ Corresponding author

(good-freedom@hanmail.net)

ORCID

Sang-Hee Kwon

http://orcid.org/0000-0001-6761-2851

\section{Images of models in womenswear advertisements targeting middle-aged women}

\author{
Sang-Hee Kwon $^{\dagger}$
}

Dept. of Fashion Design, Chonbuk National University, Korea

\section{중년 여성을 타겟으로 하는 여성복 광고에 나타난 모델 이미지}

\author{
권 상 희 ${ }^{\dagger}$ \\ 전북대학교 의류학과
}

\begin{abstract}
This study analyzes the images of models in womenswear advertisements targeting women in their fifties. The goals of this study are: 1) to investigate beauty ideals for middle-aged women by analyzing models' look age, chronological age, wrinkles, gray hair, hair length, body type, and race; and 2) to explore how ageing is dealt with in advertisements by analyzing the range of bodies shown in advertisements, the color mode of photographs, and the clarity of models' figures in relation to models' look ages. A total of 155 printed advertisements from January 2012 to January 2017 from the brands Daks Ladies, Lebeige, Luciano Choi, PAT, and Zishen were selected for analysis. Womenswear brands targeting middle-aged women reinforce cultural ideals of female beauty that emphasize youth and slenderness. They do this by using thin and slender models, who most often appear to be in their twenties and thirties, and have hair longer than their shoulders. Brands with higher price ranges show a preference for Caucasian models, which reveals that a Caucasian identity is associated with sophistication. In addition, the bodies of models who appear to be in their forties and fifties were concealed by framing photographs mostly above the knees. Older models' features were also obscured via the use of black and white photography, strong lighting and contrast, and digital editing that blurred the boundaries between figures and their backgrounds. These decisions for how to represent models could result in negative self-esteem and a denial of the symptoms of ageing among middle-aged women.
\end{abstract}

Keywords: middle age(중년), ageing(노화), model(모델), advertisement(광고), beauty ideals(이상미)

\section{Introduction}

한국의 베이비붐 세대는 한국전쟁 직후인 1955년부터 1963년 사이에 출생한 세 대로 현재 55 63세인 이들은 2017년 전체 인구의 약 14.4\%(약 740만 명)를 차지하 는 것으로 추정된다(Statistics Korea, 2017). 이들은 기존의 중장년층과 차별적인 
라이프스타일을 가지고 있어서 주목받는데, 베이비붐 세대는 고학력자이고, 경제적으로 여유가 있으며, 지 속적인 사회참여나 자아실현을 추구한다(Kim et al., 2014; Kim \& Lee, 2008). Kim et al.(2014)은 어번 그 래니(urban granny)라는 용어로 이러한 트렌드를 설 명했다. 베이비붐 세대는 자식과 손주를 위해 자신을 희생했던 과거의 할머니, 할아버지와는 달리 자신을 위해서 시간과 돈을 투자한다는 것이다. Kim and Moon(2016)에 따르면 베이비붐 세대는 이전 세대보 다 2 배 이상 지출을 하며 이러한 소비패턴은 노년기 가 되어도 유지될 것으로 예상된다. Byun(2011)과 Choi(2011) 역시 기존의 중년층과 다른 특성을 가지 는 오늘날의 중년을 '신중년'이라고 명명하고 이들의 소비력에 주목했다. 2015년 하반기 여성과 남성 패션 시장에서 50 세 이상 소비자가 차지하는 비중은 각각 $35.4 \%$ 와 $33.4 \%$ 였으며, 이는 2010 년 $21.1 \%, 27.5 \%$ 보다 큰 폭으로 상승한 것이다(Lee \& Hong, 2016). 2013년 국내 빅3 백화점인 롯데, 현대, 신세계 백화점 에서 55 세 이상 고객은 각각 $19 \%, 21 \%, 32 \%$ 의 높은 매출 비중을 차지하기도 했다(Lee, 2013).

50 대는 신체적, 정신적으로 큰 변화를 겪는 시기이 다. Lee and Chun(2015)에 따르면 50대는 중년기에 서 노년기로 넘어가는 과도기로 다양한 체형이 출현 하며, 50 대 후반부터는 허리가 굵지 않고 바른 자세 를 유지하는 체형이 급격히 감소한다. 또한 50 대 여 성은 엉덩이가 커지고, 가슴이 처지고, 배가 나오는 등 의 체형변화를 인지하며, 40 대보다 자신의 신체에 불 만족하는 비율이 높다(Lee, 2011). Raisborough, Barnes, Henwood, and Ward(2014)는 50세가 통상 나이 들었다고 간주되기 시작하는 중요한 지표라고 했고, Clark and Griffin(2008)에 따르면 여성들은 50세가 되면서 급격하게 사회의 관심에서 벗어나는 경험을 한 다. 따라서 50 대 여성은 중년과 노년의 전환점에서 자신의 정체성을 재정립하며, 이 과정에서 내적, 외적 으로 새로운 역할 학습을 위한 모델이 필요하다. $\operatorname{Twigg(2012)ㄴㅡㄴ~ㅇㅕㅅㅓㅇㄷㅡㄹㅇㅣ~ㄴㅏㅇㅣㄱㅏ~ㄷㅡㄹㅁㅕㄴㅅㅓ~ㅊㅔㅎㅕㅇㅂㅕㄴㅎㅘㅇㅔ~}$ 따라 어떻게 옷을 입으면 좋을지 확신이 없고, 나이에 맞는 옷을 입어야 한다는 문화적 압박까지 받는데, 나이든 여성을 타겟으로 하는 잡지가 연령에 맞게 옷 을 입는 방법을 제안하고 지도한다고 했다. 하지만 한국 여성잡지들은 홈페이지에 20대 중반에서 40 대
까지를 타겟으로 한다고 명시하고 있으며, 50대 이상 의 여성을 메인 타겟으로 하거나 타겟에 포함시키는 잡지는 찾아보기 힘들다. 그렇다면 중년 여성을 타겟 으로 하는 의류 브랜드의 광고는 50 대 여성에게 기대 되는 이상적인 외모를 제시하는 가장 직접적인 수단 이라고 할 수 있다.

그 동안 중년 이상의 여성을 대상으로 한 연구는 체형 분석, 의복 맞음새 개선, 소비행동, 디자인 개발 등에 집중되어 있었다. 중년 이상의 여성을 대상으로 한 연구 중 광고나 미디어 관련 연구는 시니어 의류 브랜드의 광고모델 유형에 따른 소비자 반응(Lee \& Yoh, 2016), 중년 여성의 젊음 추구와 미디어의 관계 (Jun \& Rhee, 2016), TV 미디어 관여도와 젊음 추구 의복행동(Hong, 2010) 등이 있으나, 중년 여성을 타 겟으로 하는 패션 광고가 어떠한 이미지를 전달하는 지에 대한 연구는 전무하다. 따라서 본 연구는 50 대 여성을 타겟으로 하는 여성복 광고에 나타난 모델 이 미지를 분석했다. 50 대 여성을 메인 또는 서브 타겟으 로 하는 국내 여성복 브랜드 5개를 선정하여, 2012년 1월부터 2017년 1월까지의 지면 광고를 내용분석했 으며, 연구문제는 다음과 같다. 첫째, 여성 모델의 연 령, 피부 주름과 흰머리 여부, 머리카락 길이, 체형, 인종 분석을 통해 패션 브랜드가 중년 여성에게 제시 하는 이상미를 밝힌다. 둘째, 모델의 연령에 따른 신 체 표현 범위, 광고의 컬러 유형, 인물 표현의 선명도 를 파악하여 패션 브랜드 광고가 여성의 노화를 다루 는 방식을 파악한다. 본 연구는 50 세 이상 인구의 소 비력이 주목받는 상황에서 그들을 대상으로 한 패션 광고가 어떠한 이미지를 표현하는지 살펴봄으로써 광고 전략 수립의 기초 자료로 활용될 수 있을 것이 며, 중년 여성의 정체성 형성에 패션 광고가 적합한 역 할을 하고 있는지 점검해 볼 기회를 제공할 것이다.

\section{Literature Review}

\section{Idealized images of the female body}

Thesander(1997)에 따르면 여성의 몸은 사회의 지 배적인 미적 기준에 부합하도록 변형되어 왔다. 20세 기 이전에는 풍만한 여성의 몸이 아름답다고 여겨졌 으나, 1920년경부터는 여성해방, 스포츠의 인기, 여성 의 취업과 정치 참여 등의 영향을 받아서 자유와 움 
직임을 보여주는 날씬한 몸이 선호되기 시작했으며, 날씬함이 현대적이라고 여겨졌다(Hollander, 1993). 또 한 20세기 이후 날씬함과 더불어서 탄력 있고 젊은 몸이 여성의 이상미로 여겨지고, 이상적인 몸을 가지 지 못했을 때 여성은 단순히 아름답지 않은 외모만 비판받는 것이 아니라 자기 통제력이나 의지력이 없 다고 여겨진다(Thesander, 1997). 머리 길이와 색상도 이상미와 관련이 있다. 긴 머리는 성적 매력을 보여 주는 여성스러운 특성으로 여겨지며, 남성의 흰머리 가 성숙이나 능력의 표시로 해석되는 것과 달리 여성 의 흰머리는 노화의 표시이자 매력성의 저하로 여겨 지는데, 그 결과 염색약이 암을 유발할 수 있음에도 불구하고, 40 대 이상의 많은 여성들이 흰 머리를 감추 기 위해 염색을 한다(Synnott, 1993). 패션계가 요구 하는 이상미 역시 젊고 날씬한 몸이며, 패션사진 속 모델들은 이러한 몸을 보여준다(De Perthuis, 2008). 모델의 역할은 패션상품을 홍보하고 판매하는 것에 만 국한되지 않는다. 모델의 외모는 이상미에 대한 관념을 조장하고 사회에 퍼뜨리는데, 큰 키, 날씬한 몸매, 20 대 중반 이하의 젊은 나이가 여성 모델의 보 편적인 조건이다(Mears, 2011).

여성은 나이가 들어서도 변함없는 이상미의 기준을 적용받는다. 40 80대 여성을 대상으로 포커스 그룹 인터뷰를 실시한 Song(2012)에 따르면 중 - 노년 여 성들은 노화로 인한 신체적, 외모적 변화를 부정적으 로 보았고, 나이가 들면서 가꾸지 않으면 추해보이고 남에게 혐오감을 준다는 의미를 공유했다. Jang and Yoo(2011)에 따르면 40 50대 여성들이 이상적이라 고 생각하는 신체치수는 키 $165.4 \mathrm{~cm}$, 체중 $52 \mathrm{~kg}$, 허리 둘레 26.3inch로, 실제 신체보다 키는 더 크고 체중과 허리둘레는 작은 몸을 선호했다. Lewis and Cachelin (2001)은 중 - 노년 여성의 경우, 노화에 대한 두려움이 클수록 마른 몸에 대한 열망 및 섭식장애 발생률이 높은 것을 발견했다. 40 50대 여성들을 심층면접한 Yoo (2014)에 따르면 중년 여성은 뚱뚱한 몸을 지양하고, 근육과 볼륨감이 있고, 날씬한 몸을 이상적이라고 여 겼으며, 이러한 몸을 가지면 젊어 보인다고 생각했다. 또한 Lee and Yoh(2016)의 연구에서 중·노년 여성 들은 마른 체형의 모델을 아름답고 세련되다고 느꼈 을 뿐만 아니라, 평균 체형보다 마른 체형의 모델을 더 젊게 지각했다. 이러한 연구결과들은 중 - 노년 여
성에게 날씬함은 곧 젊음을 의미하며, 그들이 생각하 는 아름다움이 젊음과 매우 밀접한 관련이 있음을 보 여준다.

\section{Images of older female models in mass media and advertising}

1) Under-representation and negative images of older women

Coupland(2009), Kim(2010), Ko(2016), Swayne and $\mathrm{Greco}(1987)$ 를 비롯한 다수의 선행 연구들은 TV, 신 문, 잡지 광고에서 나이든 모델의 등장 빈도가 낮으 며, 등장하더라도 무력하고, 무식하고, 매력적이지 않 은 부정적인 모습으로 묘사되는 것을 지적했다. 나이 든 모델이 등장하는 광고는 의약품, 보청기, 요양시설, 기능성 화장품 등으로 품목이 제한되어 있고(Carrigan \& Szmigin, 1999; Kim \& Won, 1999), 설령 다양한 광고에 등장하더라도 단독으로 비중 있는 역할을 하 는 광고는 의약품, 보험, 상조, 정부 광고 등에 한정된 다(Park, 2009; Simcock \& Sudbury, 2006). 나이든 모 델이 광고에 잘 등장하지 않는 이유는 광고회사 간부 들이 다양한 연령대의 소비자에게 나이든 모델이 호 소력이 있을지 걱정하고(Greco, 1988), 광고 실무자 들이 나이든 모델 자체를 고려하지 않거나, 매력적으 로 여기지 않으며(Kim, 2001), 구매 습관이 어릴 때 형성되기 때문에 구매 패턴이 잘 변하지 않는 중·노 년층보다 젊은층을 공략해야 한다는 고정관념이 존 재하기 때문이다(Cohen, 2013).

특히 나이든 여성이 남성보다 광고에 등장하는 빈 도가 현저히 낮은데(Kim, 2010; Kim \& Won, 1999; Ko, 2016; Park, 2009; Simcock \& Sudbury, 2006), 이는 남성보다도 여성의 노화가 더욱 부정적으로 인 식되는 것을 드러낸다. 앞에서 고찰했듯이, 젊음이 여 성의 이상미와 밀접하게 연관되어 있기 때문에 여성 의 노화는 정신적, 육체적 쇠약뿐만 아니라, 매력성의 저하와 연결지어진다(Clarke \& Griffin, 2008). 외적 인 아름다움을 극대화하여 보여주는 패션잡지는 사 회가 여성의 노화를 매력성의 측면에서 어떻게 보는 지를 잘 드러내는 매체이다. Kwon and Helvenston (2006)에 따르면, 2002년 미국 Vogue에서 중년과 노 년 여성 모델이 등장한 광고는 각각 $4.4 \%, 0.4 \%$ 인 반 
면, 미국 $\mathrm{GQ}$ 에서 중년과 노년 남성 모델이 등장한 광 고는 각각 $16 \%, 1.3 \%$ 로 나이든 여성 모델의 등장 비 율이 남성보다 현저하게 낮았다. 또한 남성보다 여성 을 대상으로 한 광고에서 주름 방지 크림과 머리 염 색 등 나이를 감추는데 필요한 제품 광고가 많이 나 타나서, 여성에게 더 젊은 이미지가 요구됨을 보여줬 다(Kwon \& Helvenston, 2006).

나이든 여성은 광고뿐만 아니라, 패션잡지의 표지 와 기사에서도 찾아보기 힘들다. 1990년부터 2009년 까지 영국 Vogue의 표지와 기사를 분석한 Twigg (2010)에 따르면, Vogue에서 나이든 여성은 거의 등 장하지 않는다. 설령 등장하더라도 특집 기사나 노화 방지에 관한 뷰티 기사에 한정되거나, 노화가 최대한 드러나지 않는 방식으로 표현되거나, 모델로서가 아 니라 실존하는 유명인의 삶을 소개할 때 나타난다. Vogue는 노화된 모습을 부각시키지 않기 위해서 20, 30,40 대를 함께 등장시키는데, 이 경우에도 50 대 이 상은 자주 나오지 않으며, 등장하더라도 성형수술과 사진 보정으로 노화를 감춘 모습으로 표현된다. 또한 나이든 여성은 젊은 여성에 비해 작은 사진으로 나타 나고, 젊은 시절의 사진이나 젊은 딸과 함께 등장하 기도 하며, 어둡게 표현되어서 노화의 흔적이 가려진 다(Twigg, 2010). Halls(2000)에 따르면 우아함을 추 구하던 1940년대 후반과 1950년대까지만 하더라도 영국 Vogue는 흰머리가 있는 50 60세 정도의 허구의 여성 Mrs. Exeter를 삽화나 사진에 정기적으로 등장 시켰으며, 표지 모델로 쓰기도 했다. 하지만, Mrs. Exeter는 점점 50 대보다 젊은 외모로 등장하고, 전신 사진으로 표현되지 않는 등의 변화를 겪다가 본격적 으로 젊음이 추구되기 시작한 1960년대부터는 사라 지게 되었다(Halls, 2000).

광고에서 나이든 여성 모델의 낮은 등장 비율은 나 이든 여성의 구매의사 저하로 이어질 위험이 있다. 동일한 패션 광고에서 모델의 연령을 조작한 Kozar (2010, 2012), Kozar and Damhorst(2008)에 따르면 30 80세 여성들은 젊은 모델보다 나이든 모델이 등 장한 패션 광고를 제품 구매 의사, 모델의 매력성, 제 품의 패션성 측면에서 더 긍정적으로 평가했다. 또한 Lee and Yoh(2016)의 연구에서는 65세 이상 소비자 의 경우 모델 이미지와 자아 이미지의 차이가 클수록 모델에 부정적인 태도를 가졌다. 이러한 결과는 젊은
모델이 등장하는 광고가 항상 긍정적인 효과를 가져 오는 것은 아님을 시사한다.

\section{2) Commercialized images of youthful and healthy} looking women

나이든 모델이 잘 등장하지 않거나, 부정적으로 묘 사되던 과거와 달리 최근으로 올수록 나이든 모델이 비중 있게 다뤄지거나, 젊고 건강하고 긍정적인 모습 으로 표현되는 경향이 나타난다. 시사교양지, 여성잡 지, 스포츠레저 잡지를 분석한 $\operatorname{Kim}(2010)$ 은 1978,1988 , 1998년보다 2008년 잡지 광고에서 노년 모델이 비중 있는 역할을 하고, 다양한 제품 범주에 등장하며, 패 션제품 광고에서 노년 모델이 새롭게 등장함을 발견 했다. 2008년부터 2016년까지 건강잡지 광고를 분석 한 $\mathrm{Ko}(2016)$ 역시 노년 모델이 등장하는 빈도가 여전 히 낮기는 하지만, 과거에 비해 단독이나 주연으로 등장하는 경우가 많으며, 능동적이고 긍정적인 이미 지로 묘사된다고 했다. 특히 여성 노인을 경제적으로 어렵고 의존적인 모습으로 묘사하던 과거와 달리, 젊 고 건강하며, 독립적인 모습으로 묘사하는 경향이 나 타났으며, 노인 모델이 다양한 제품 범주에서 나타났 고, 화장품 및 패션제품 광고에서의 출현이 증가했다 (Ko, 2016). 2012년경부터 Lanvin, Saint Laurent, Celine, Versace, The Row, American Apparel 등 다수의 해외 패션 브랜드들은 이례적으로 50 90대 여성 모 델을 광고에 단독으로 비중 있게 등장시켜서 주목받 기도 했다(Im, 2016; Kim, 2015).

그러나 미디어와 광고에서 나이든 모델이 비중 있 고 젊게 다뤄지는 데에는 상업적인 배경이 작용하며, 이것은 과도한 젊음추구 현상을 일으킬 수 있다. Twigg (2010)에 따르면 Vogue는 실제 나이보다 몇 십 년 젊 어 보이는 여성을 반복적으로 등장시키고, 이상적으 로 묘사함으로써, 나이든 여성도 젊은 외모를 추구하 면 소비문화의 주류로 남아있을 수 있다고 홍보한다. 또한 잡지 광고나 $\mathrm{TV}$ 프로그램은 관리하기 전, 후의 이미지를 대조함으로써 나이 들어 보이는 것을 부끄 러운 것으로 묘사하며, 피부, 체형, 몸무게, 헤어스타 일, 의복을 잘 관리하면 젊어 보일 수 있다는 메시지 를 전달한다(Coupland, 2009). 미디어는 경제력과 자 기관리를 통해 노화를 제어할 수 있는 것으로 표현하 고, 실제 나이보다 비현실적으로 젊고 건강한 이미지 
를 보여줌으로써, 경제력이 없거나 자기관리에 실패 했다고 여겨지지 않기 위해 안티에이징(anti-aging) 소비를 하도록 부추긴다(Raisborough et al., 2014). 그 결과, 실제 나이보다도 몇 살로 보이는지가 중요 해졌으며, 미디어는 실제 나이와 보이는 나이의 차이 를 강조하여 젊은 외모를 유지하기 위한 소비를 이끌 어낸다(Clark \& Griffin, 2008).

Jun and Rhee(2016)에 따르면 40 65세 여성들이 매력적으로 보이기 위해 젊음을 추구할수록 TV 미디 어의 외모 관련 정보에 적극적인 관심을 가졌고, 미 디어의 외모 관련 정보에 관심이 높을수록 적극적인 구매 의도나 구매 행동을 보였다. 또한 $\operatorname{Hong}(2010)$ 에 따르면 40 50대 여성의 TV 미디어 관여도가 높을수 록 젊음추구 의복행동이 높았다. $\mathrm{Yoo}(2014)$ 와 Song (2012) 역시 각각 심층면접과 포커스 그룹 인터뷰를 통해 중 - 노년 여성이 젊고 날씬한 외모를 추구하는 배경 중 하나로 광고와 매스미디어의 영향을 발견했 다. 이러한 연구 결과들은 광고와 미디어가 중년 여 성의 젊음추구 행동에 중요한 정보원이 되며 영향력 을 행사함을 보여준다.

정리하자면, 미디어와 광고는 나이든 사람에 대한 고정관념을 형성하고, 나이든 사람들이 노화에 대처 하는 방식에 영향을 준다. 과거에는 미디어와 광고에 나이든 사람이 거의 등장하지 않거나, 병들고 매력적 이지 않게 묘사되어 부정적인 고정관념이 형성되었 다면, 최근에는 지나치게 젊고 건강하고 활력 있게 묘사되는 경향이 있다. 이로 인해 노화 현상이 잘못 된 자기관리나 부족한 경제력의 결과이며, 감춰야 하 는 것처럼 여겨지고 결과적으로 미디어와 광고는 나 이든 여성의 젊음추구 행동과 소비를 부추긴다.

\section{Research Methods}

50대 여성을 타겟으로 하는 여성복 브랜드의 광고 를 분석하기 위한 브랜드 선정 방법은 다음과 같다. Firstviewkorea(2012a，2012b, 2013a，2013b, 2014a, $2014 \mathrm{~b}, 2015 \mathrm{a}, 2015 \mathrm{~b}, 2016 \mathrm{a}, 2016 \mathrm{~b})$ 의 소비자 리포 트를 바탕으로 50 대 여성이 정장, 캐주얼 의류를 자 주 구매했다고 응답한 브랜드를 정리하여 110 개의 목 록을 얻었다. 그 중에서 Apparelnews(2014)를 참고하 여 내셔널 또는 라이센스 브랜드 중 50 대를 메인이나
서브 타겟으로 하는 여성복 브랜드를 추려낸 결과, 닥 스 숙녀, 지센, PAT, 손정완, 이동우 콜렉션이 있었 다. 이 중에서 지면 광고를 하지 않는 손정완, 이동우 콜렉션을 제외시켰고, 50대를 타겟으로 하는 브랜드 중 활발하게 지면 광고를 하는 르베이지, 루치아노최 를 추가했다. 분석 브랜드의 타겟 연령 및 가격대는 〈Table 1〉과 같다.

광고 수집 및 선정 방법은 다음과 같다. 해당 브랜 드의 홈페이지와 Advertising Information Center(ADIC) 에서 지면 광고를 수집했으며, 2012년 1월부터 2017 년 1월까지의 광고 중 $\mathrm{Ko}(2016), \mathrm{Kim}(2010)$ 의 표집 방법을 참고하여 애드버토리얼을 제외하고 여성 모 델이 등장하면서 사진이 전체 페이지의 2 분의 1 이상 을 차지하는 광고 사진 183 장을 수집했다. 모델, 의 상, 포즈가 동일하다면 배경이나 광고 문구가 바뀌었 어도 같은 광고라고 보았고, 중복 광고와 얼굴 없이 신체 일부만 나온 광고를 제외시켜서 총 155 장의 광 고 사진을 분석했다.

분석 항목은 총 10 가지로 여성 모델의 보이는 연 령, 실제 연령, 피부 주름 여부, 흰머리 여부, 머리카 락 길이, 체형, 인종, 신체 표현 범위, 광고의 컬러 유 형, 인물 표현의 선명도였으며, 분석 방법은 다음과 같다. 메인 모델 뒤에 사진의 2 분의 1 이하 크기의 인 물이 등장하는 경우는 배경으로 간주하여 인물 분석 에서 제외시켰다. 모델의 보이는 연령은 $\operatorname{Kim}(2010)$, Park(2009), Simcock and Sudbury(2006)를 참고하여 인상, 흰머리, 탈모, 손과 얼굴의 주름, 자세 등을 토 대로 추론하여 10 대부터 50 대까지로 나누었으며, 얼 굴을 돌리고 있거나 그림자 때문에 얼굴이 보이지 않 는 경우는 식별불가로 분류했다. 실제 연령은 $\mathrm{ADIC}$

$<$ Table 1> Target age and price range of selected brands

\begin{tabular}{c|c|c}
\hline Brand & Target age & Price range \\
\hline Daks Ladies & $45 \sim 55$ & Middle to high \\
\hline Lebeige & $45 \sim 55$ & High \\
\hline Luciano Choi & 50 & High \\
\hline PAT & $41 \sim 50$ & Middle \\
\hline Zishen & Main: 40, Sub: $35 \sim 50$ & Middle \\
\hline
\end{tabular}

From. Apparelnews. (2014). pp. 113, 126, 127, 184, 200. 
의 모델정보 및 구글과 네이버에 있는 모델의 프로필 을 검색하여 파악했으며, 유명인이 아니어서 검색이 안 되는 경우는 알 수 없음으로 분류했다. 주름은 표 정 때문에 생기는 것은 제외하고, 특별한 표정을 짓 지 않아도 나타나는 얼굴과 손의 주름을 분석했다. 머리카락 길이와 체형은 Kwon and Helvenston(2006) 의 분류 항목을 본 연구에 맞게 변형시켰으며, 인종 은 Lee (2009)를 참고하여 백인, 흑인, 동양인으로 분 류했다. 신체 표현 범위는 가슴, 허리, 엉덩이, 무릎, 발목, 발끝까지로 분류했으며, 두 지점의 사이에서 사 진이 끝나서 판단이 애매한 경우에는 이전 부위까지 로 분류했다. 가령 〈Fig. 1〉, 〈Fig. 7〉처럼 엉덩이와 무 릎 사이에서 사진이 끝났고, 무릎이 보이지 않으면 엉덩이까지로 분류했다. 광고의 컬러 유형은 흑백과 컬러로 분류했으며, 인물 표현의 선명도는 Twigg(2010) 가 언급한 Vogue에서 나이든 여성의 노화를 가리는 방식을 참고하여, 강한 그림자나 빛이 모델의 일부를 가리거나, 디지털 합성을 통해 배경과 모델의 경계를 모호하게 만들었을 경우, 선명도가 낮고 불분명하다 고 보았다.

주관적인 판단을 최소화하기 위해 연구자(30대)를 포함하여 의류학 석사학위를 가진 30 대 여성 1 명과 50 대 일반인 여성 2 명, 총 4 명이 분석에 참여했다. Ursic, Ursic, and Ursic(1986)은 60세 이상 모델이 등장한 잡 지광고를 분석할 때 60 대 남녀 2명을 분석자로 했는 데, 본 연구는 이를 참고하여 분석자에 50 대 여성을 포 함시켰다. 그 이유는 모델의 보이는 연령과 체형 분 석 시 타겟 연령대 여성의 판단이 유의미할 것이라고 보았기 때문이다. 분석에 앞서 연구자가 다른 분석자 들에게 분석 항목과 기준에 대해 충분히 설명했으며, 서로 분석이 불일치할 경우 각 분석자에게 분석의 근 거를 물어보았다. 만약 근거가 타당하지 않거나, 분석 기준을 잘못 이해했을 경우, 분석 기준을 다시 설명하 고 재분석하게 했다. 사진마다 다수결에 기초하여 분 석 결과를 정리했으며, 각 항목에 대해 SPSS ver.18.0 을 이용하여 빈도분석과 교차분석을 실시했다.

\section{N. Results and Discussion}

총 155 장의 광고 사진 중 $12.9 \%$ 에는 한 명의 남 성 모델, $0.6 \%$ 에는 두 명의 남성 모델이 여성 모델과
함께 등장했다. 남성 모델은 동일한 브랜드 이름으로 남성복도 판매하는 닥스, PAT, 지센의 광고에서만 나 타났고, 남성 상품을 함께 보여주기 위한 것이었다. 남 성 모델을 제외하면 모든 광고에 메인 여성 모델이 한 명씩 등장하여 총 155 명의 여성 모델이 등장했다.

여성 모델의 보이는 연령을 조사한 결과, 모든 브 랜드에서〈Fig. 1〉, 〈Fig. 2〉처럼 30대로 보이는 모델 이 가장 높은 비율을 차지했으며, 전체 모델 중 이들 이 차지하는 비율을 $54.2 \%$ 였다. 그 다음으로는 〈Fig. 3 , 〈Fig. 4〉처럼 20대로 보이는 모델이 $23.2 \%$ 를 차지 했다. 한편, 〈Fig. 5〉 〈Fig. 7〉처럼 40대로 보이는 모 델은 $16.8 \%$ 였으며, 〈Fig. 8〉, 〈Fig. 9〉처럼 50대로 보 이는 모델은 $3.9 \%$ 에 불과했다. 사진의 $1.9 \%$ 는 얼굴 을 돌리고 있거나, 얼굴의 그림자 때문에 나이를 식별 할 수 없었다. 모델의 실제 연령을 조사한 결과, 연령 을 알 수 없는 경우가 $49.7 \%$ 로 가장 많았다. 그 이유 는 르베이지는 교수, 사업가, 작가, 잡지 에디터 등 다 수의 일반인을 모델로 기용했고, 다른 브랜드들은 인 지도가 낮은 전문 모델을 기용하여 이름이나 프로필

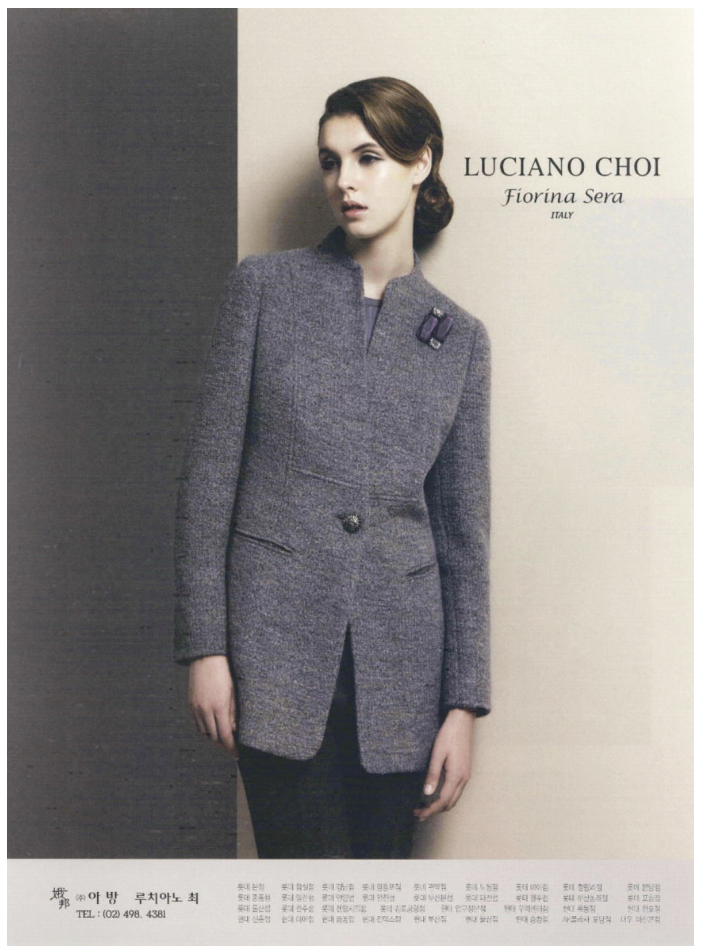

<Fig. 1> Luciano Choi

From. ADIC. (2014). https://www.adic.or.kr 


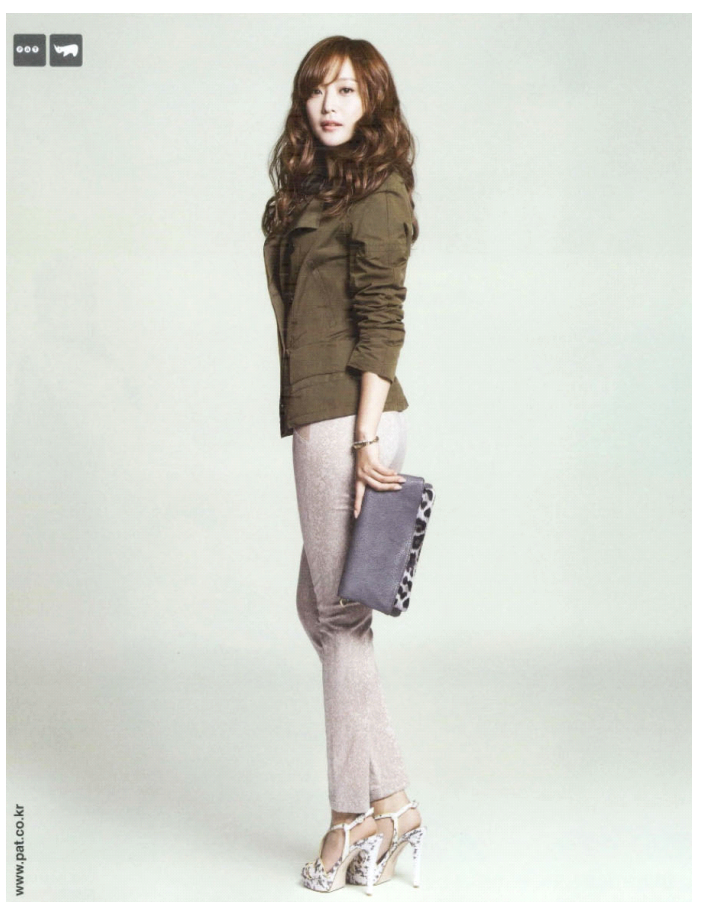

<Fig. 2> PAT

From. ADIC. (2013a). https://www.adic.or.kr

을 알 수 없었기 때문이다. 유명인 모델을 기용한 나 머지 $50.3 \%$ 는 실제 연령을 알 수 있었는데, 30 대 모델 이 $32.3 \%$ 로 가장 많았고, 40 대가 $9.7 \%, 20$ 대가 $5.8 \%$ 였으며, 50 대는 한 명 뿐이었다( $0.6 \%)$. 그러나 유일한 50 대 유명인 모델이 등장한 〈Fig. 5〉에서 51세의 배 우 황신혜는 50 대로 보이지 않는 젊은 얼굴과 군살 없는 몸매를 보여준다. 한편, 40,50 대를 타겟으로 함 에도 불구하고, 닥스와 르베이지 광고에는 10 대 모델 이 등장하기도 했다(Table 2). 모델의 연령 분석 결과 에서 알 수 있는 것은 조사 브랜드들이 타겟보다 젊 은 모델 또는 젊어 보이는 모델을 선호하며, 실제 타 겟 연령으로 보이는 모델은 자주 등장시키지 않는다 는 것이다. 특히 50 대 모델이나 50 대로 보이는 모델 은 거의 등장하지 않으며, 오직 르베이지 광고에서만 나타났다. 40대로 보이는 모델 역시 대부분 르베이지 모델이어서 타 브랜드들이 젊은 모델을 선호하는 경 향이 더 심한 것을 알 수 있다. PAT와 지센은 오로지 20,30 대로 보이는 모델만을 기용했다.

눈가, 입가, 손의 주름, 팔자 주름 등 피부 주름과 흰머리는 노화를 드러내는 대표적인 요소이다. 전체 광

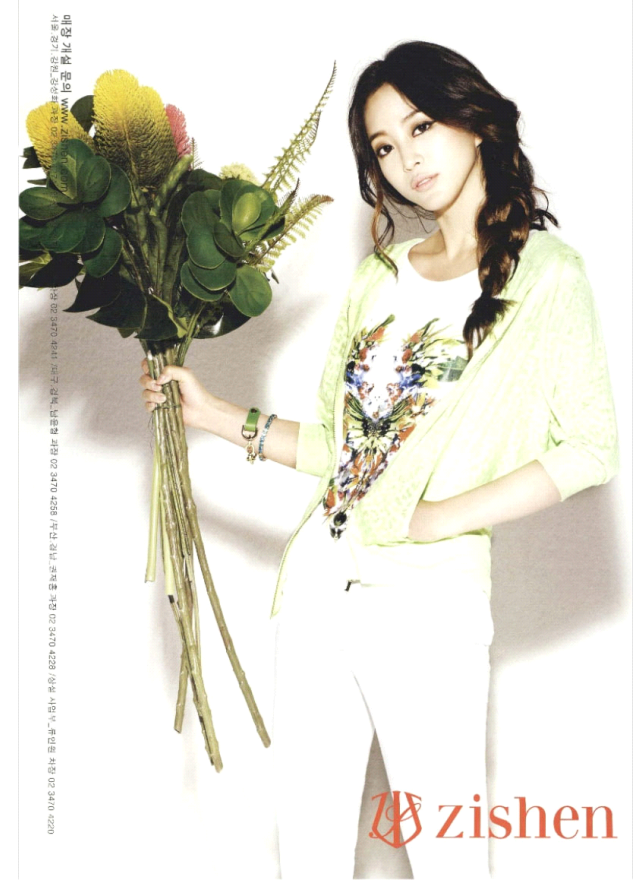

<Fig. 3> Zishen

From. ADIC. (2013b). https://www.adic.or.kr

고 중 노화로 인한 피부 주름이 보이는 경우는 $9.0 \%$ 에 불과했으며, 주름은 르베이지 광고에서만 나타났 다. 주름이 나타나는 경우에도 언뜻 보아서는 식별되 지 않을 정도로 미미했으며, 〈Fig. 8〉이 주름이 가장 분명하게 나타난 광고이다. $3.2 \%$ 는 고개를 돌리고 있 거나, 그림자, 빛, 선글라스 때문에 주름 판별이 어려 웠다. 한편, 흰머리가 나타난 사진은 한 장도 없었으 며, 식별 불가능한 경우(6.5\%)는 〈Fig. 9〉처럼 흑백 사진이어서 흰머리인지 금발인지 구분이 어려웠다.

모델의 머리카락 길이는 어깨 아래가 $44.5 \%$ 로 가장 많았다. 그 다음으로 높은 비율을 차지한 것은 식별불 가(27.1\%)였는데, 식별이 어려운 이유는 머리카락이 상의 안으로 들어가 있거나, 머리를 묶고 있거나, 올 림머리를 했기 때문이다. 하지만 이러한 연출이 가능 하려면 머리카락이 어깨 길이 이상이 되어야 하기 때 문에 사실상 어깨 아래 길이가 $50 \%$ 이상이라고 볼 수 있다. 일반적인 경우, 50 대 이상 여성이 어깨 아래로 길게 머리를 기른 경우는 많지 않다. 40,50 대를 타겟으 로 하는 브랜드 광고에서 모델들이 긴 머리카락을 보 여주는 이유는 모델의 실제 나이가 타겟보다 젊거나, 


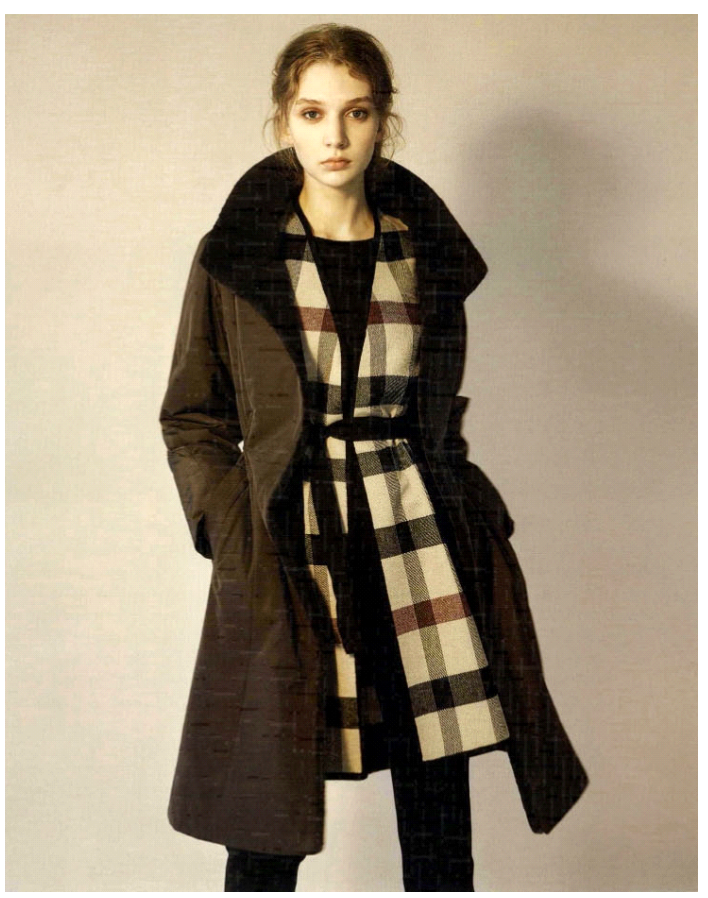

<Fig. 4> Daks Ladies

From. ADIC. (2016). https://www.adic.or.kr

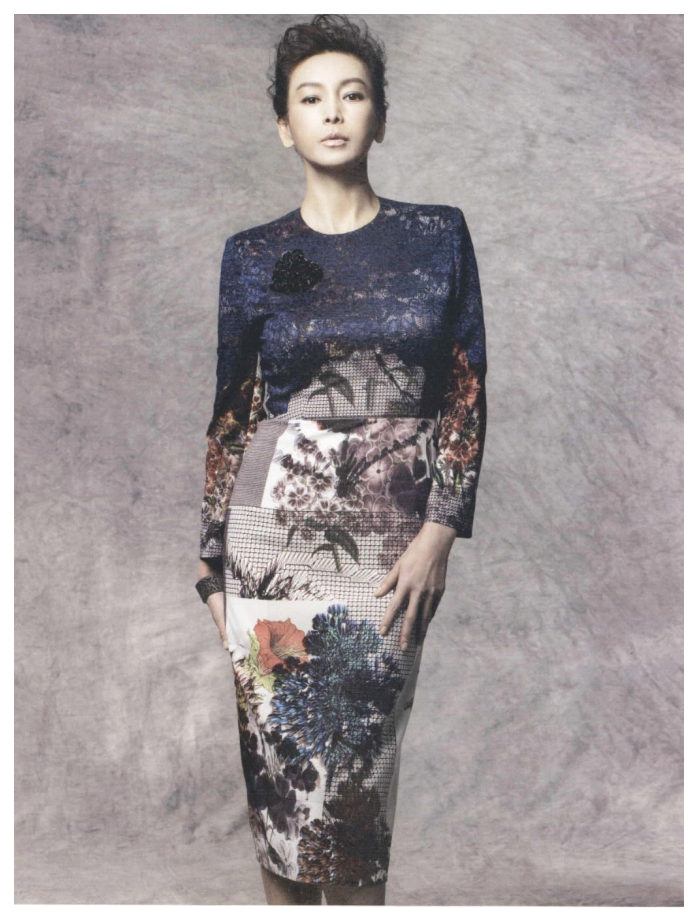

$<$ Fig. 5> Lebeige

From. ADIC. (2013c). https://www.adic.or.kr

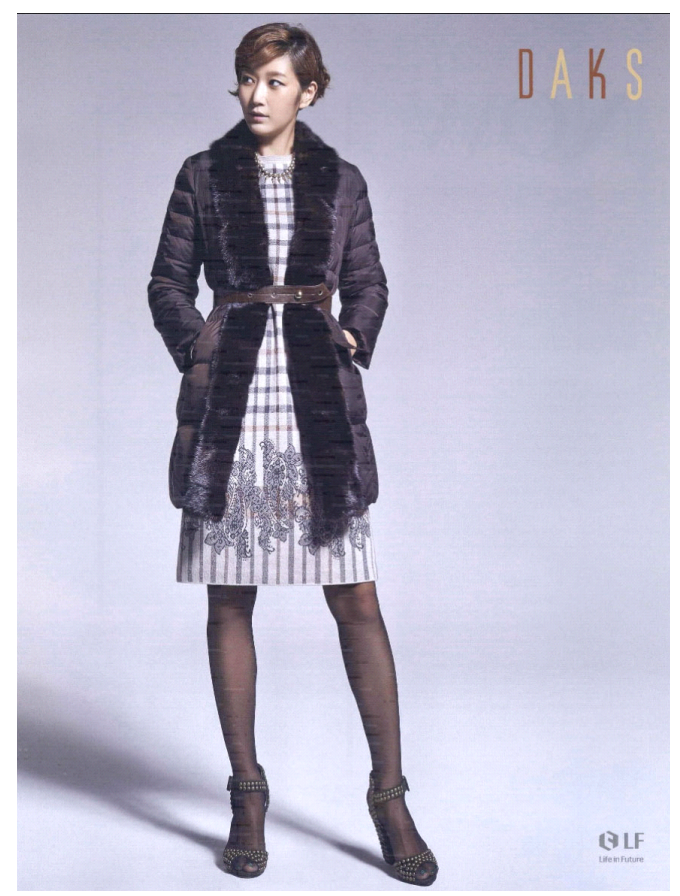

<Fig. 6> Daks Ladies

From. ADIC. (2015). https://www.adic.or.kr

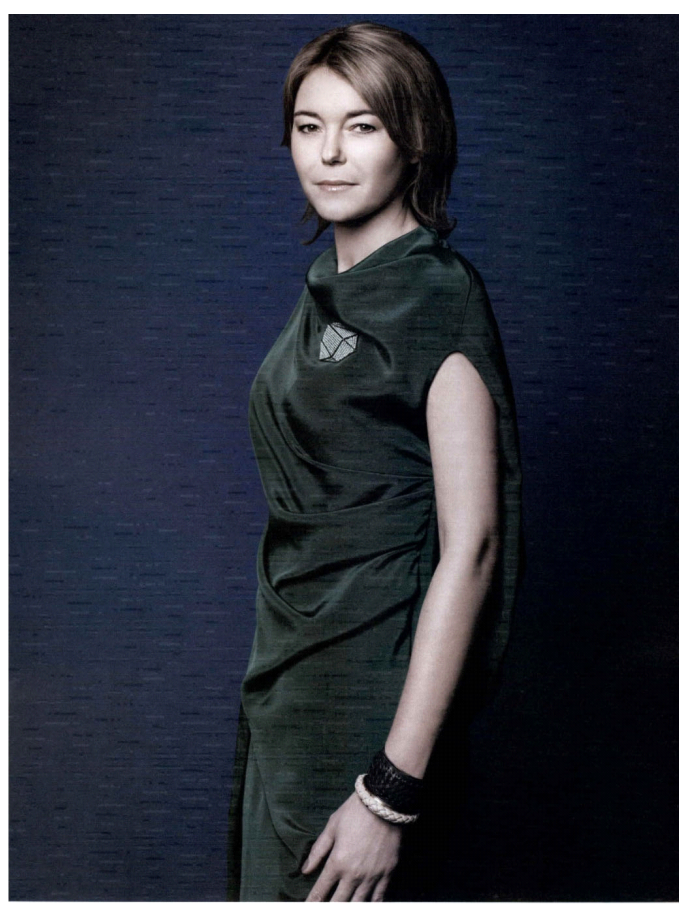

$<$ Fig. 7> Lebeige

From. ADIC. (2012a). https://www.adic.or.kr 


\begin{tabular}{|c|c|c|c|c|c|c|c|}
\hline & & \multicolumn{5}{|c|}{ Brand } & \multirow{2}{*}{$\begin{array}{c}\text { Total } \\
(N=155)\end{array}$} \\
\hline & & $\begin{array}{c}\text { Daks Ladies } \\
\quad(n=15)\end{array}$ & $\begin{array}{l}\text { Lebeige } \\
(n=58)\end{array}$ & $\begin{array}{l}\text { Luciano Choi } \\
\qquad(n=35)\end{array}$ & $\begin{array}{c}\text { PAT } \\
(n=32)\end{array}$ & $\begin{array}{l}\text { Zishen } \\
(n=15)\end{array}$ & \\
\hline \multirow{6}{*}{ Look age } & $10 \mathrm{~s}$ & $0(\quad 0.0)$ & $0(\quad 0.0)$ & $0(\quad 0.0)$ & $0(\quad 0.0)$ & $0(\quad 0.0)$ & $0(0.0)$ \\
\hline & $20 \mathrm{~s}$ & $5(33.3)$ & $4(\quad 6.9)$ & $13(37.1)$ & $7(21.9)$ & $7(46.7)$ & $36(23.2)$ \\
\hline & $30 \mathrm{~s}$ & $7(46.7)$ & $24(41.4)$ & $20(57.1)$ & $25(78.1)$ & $8(53.3)$ & $84(54.2)$ \\
\hline & $40 \mathrm{~s}$ & $2(13.3)$ & $22(37.9)$ & $2(5.7)$ & $0(\quad 0.0)$ & $0(\quad 0.0)$ & $26(16.8)$ \\
\hline & $50 \mathrm{~s}$ & $0(\quad 0.0)$ & $6(10.3)$ & $0(\quad 0.0)$ & $0(\quad 0.0)$ & $0(\quad 0.0)$ & $6(3.9)$ \\
\hline & Indiscernible & $1(\quad 6.7)$ & $2(3.4)$ & $0(\quad 0.0)$ & $0(\quad 0.0)$ & $0(\quad 0.0)$ & $3(1.9)$ \\
\hline \multirow{6}{*}{$\begin{array}{c}\text { Chronological } \\
\text { age }\end{array}$} & $10 \mathrm{~s}$ & $1(\quad 6.7)$ & $2(3.4)$ & $0(\quad 0.0)$ & $0(\quad 0.0)$ & $0(\quad 0.0)$ & $3(1.9)$ \\
\hline & $20 \mathrm{~s}$ & $3(20.0)$ & $2(3.4)$ & $0(\quad 0.0)$ & $4(12.5)$ & $0(\quad 0.0)$ & $9(5.8)$ \\
\hline & $30 \mathrm{~s}$ & $3(20.0)$ & $6(10.3)$ & $0(\quad 0.0)$ & $26(81.3)$ & $15(100.0)$ & $50(32.3)$ \\
\hline & $40 \mathrm{~s}$ & $2(13.3)$ & $13(22.4)$ & $0(\quad 0.0)$ & $0\left(\begin{array}{ll}0.0\end{array}\right)$ & $0(\quad 0.0)$ & $15(9.7)$ \\
\hline & $50 \mathrm{~s}$ & $0(\quad 0.0)$ & $1(1.7)$ & $0(\quad 0.0)$ & $0(\quad 0.0)$ & $0(\quad 0.0)$ & $1(0.6)$ \\
\hline & Unknown & $6(40.0)$ & $34(58.6)$ & $35(100.0)$ & $2(6.3)$ & $0(\quad 0.0)$ & $77(49.7)$ \\
\hline \multirow{3}{*}{ Wrinkles } & No & $13(86.7)$ & $41(70.7)$ & $35(100.0)$ & $32(100.0)$ & $15(100.0)$ & $136(87.7)$ \\
\hline & Yes & $0(\quad 0.0)$ & $14(24.1)$ & $0(\quad 0.0)$ & $0(\quad 0.0)$ & $0(\quad 0.0)$ & $14(9.0)$ \\
\hline & Indiscernible & $2(13.3)$ & $3(5.2)$ & $0(\quad 0.0)$ & $0(\quad 0.0)$ & $0(\quad 0.0)$ & $5(3.2)$ \\
\hline \multirow{3}{*}{ Gray hair } & No & $15(100.0)$ & $48(82.8)$ & $35(100.0)$ & $31(100.0)$ & $15(100.0)$ & $145(93.5)$ \\
\hline & Yes & $0(\quad 0.0)$ & $0(\quad 0.0)$ & $0(\quad 0.0)$ & $0(\quad 0.0)$ & $0(\quad 0.0)$ & $0(0.0)$ \\
\hline & Indiscernible & $0(\quad 0.0)$ & $10(17.2)$ & $0(\quad 0.0)$ & $0(\quad 0.0)$ & $0(\quad 0.0)$ & $10(6.5)$ \\
\hline \multirow{4}{*}{ Hair length } & $\begin{array}{c}\text { Between the ear } \\
\text { and shoulder }\end{array}$ & $2(13.3)$ & $4(6.9)$ & $2(5.7)$ & $17(53.1)$ & $0(\quad 0.0)$ & $25(16.1)$ \\
\hline & Shoulder length & $0(\quad 0.0)$ & $11(19.0)$ & $0(\quad 0.0)$ & $5(15.6)$ & $3(20.0)$ & $19(12.3)$ \\
\hline & $\begin{array}{c}\text { Longer than } \\
\text { shoulders }\end{array}$ & $4(26.7)$ & $33(56.9)$ & $13(37.1)$ & $8(25.0)$ & $11(73.3)$ & $69(44.5)$ \\
\hline & Indiscernible & $9(60.0)$ & $10(17.2)$ & $20(57.1)$ & $2(6.3)$ & $1(\quad 6.7)$ & $42(27.1)$ \\
\hline \multirow{4}{*}{ Body type } & Thin & $6(40.0)$ & $5(8.6)$ & $6(17.1)$ & $2(6.3)$ & $3(20.0)$ & $22(14.2)$ \\
\hline & Slender & $9(60.0)$ & $43(74.1)$ & $29(82.9)$ & $30(93.8)$ & $12(80.0)$ & $123(79.4)$ \\
\hline & Fleshy & $0(\quad 0.0)$ & $2(3.4)$ & $0(\quad 0.0)$ & $0(0.0)$ & $0(\quad 0.0)$ & $2(1.3)$ \\
\hline & Indiscernible & $0(\quad 0.0)$ & $8(13.8)$ & $0(\quad 0.0)$ & $0(\quad 0.0)$ & $0(\quad 0.0)$ & $8(5.2)$ \\
\hline \multirow{3}{*}{ Race } & Caucasian & $10(66.7)$ & $51(87.9)$ & $35(100.0)$ & $4(12.5)$ & $0(\quad 0.0)$ & $100(64.5)$ \\
\hline & Black & $0(\quad 0.0)$ & $0(\quad 0.0)$ & $0(\quad 0.0)$ & $0(\quad 0.0)$ & $0(\quad 0.0)$ & $0(0.0)$ \\
\hline & Asian & $5(33.3)$ & $7(12.1)$ & $0.0)$ & $28(87.5)$ & $15(100.0)$ & $55(35.5)$ \\
\hline
\end{tabular}




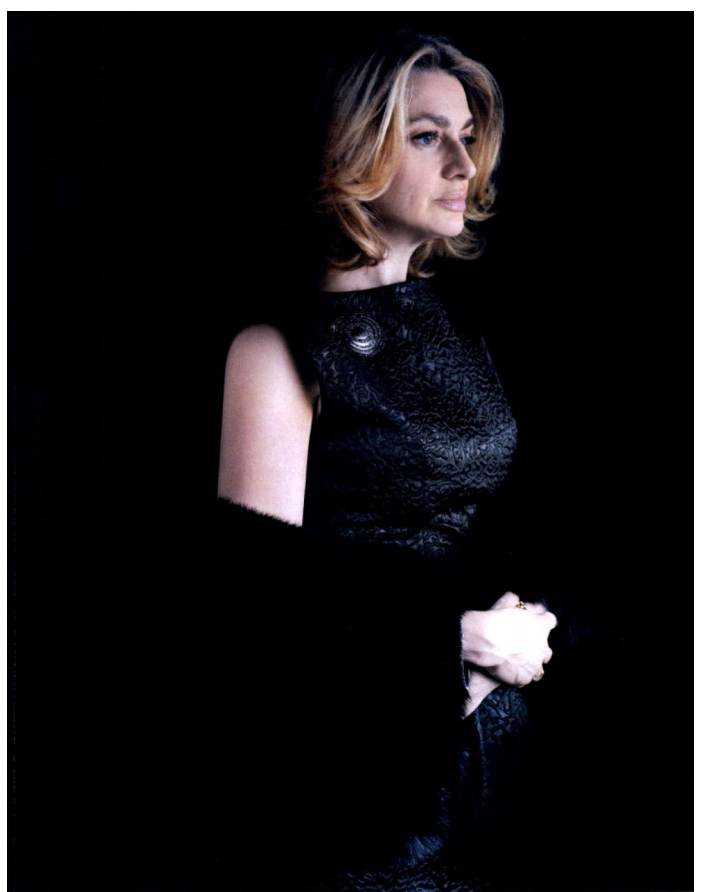

<Fig. 8> Lebeige

From. ADIC. (2012b). https://www.adic.or.kr

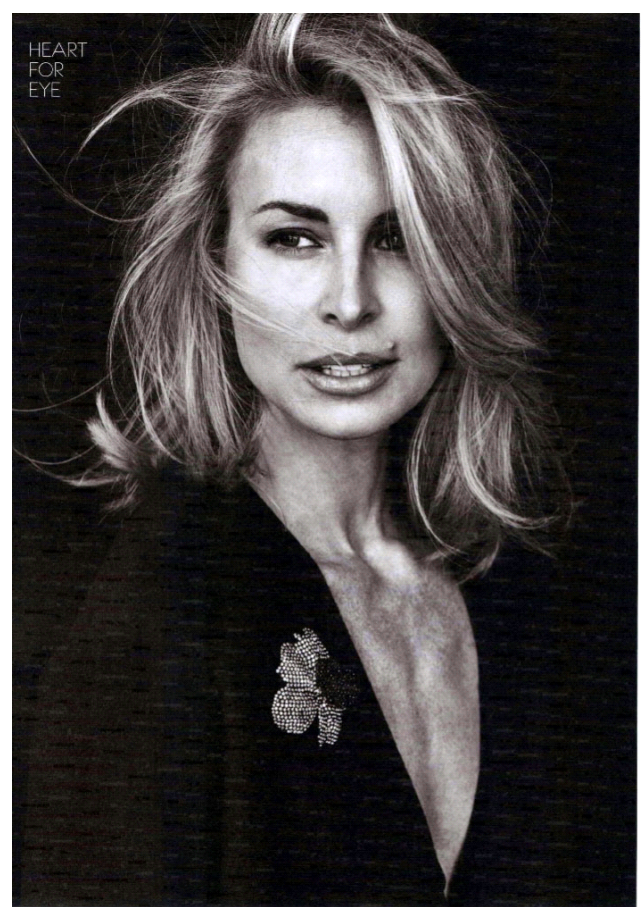

$<$ Fig. 9> Lebeige

From. ADIC. (2017). https://www.adic.or.kr
광고가 젊은 이미지를 지향하기 때문으로 보인다.

모델의 체형은 날씬한 체형이 $79.4 \%$ 로 가장 많았고, 마른 체형이 $14.2 \%$ 였다. 통통한 체형은 $1.3 \%$ 에 불과 했고, 이 경우에도〈Fig. 7〉처럼 다른 모델에 비해 약 간 통통해 보일 뿐, 모델이 아니라 40,50 대의 일반인 이라면 날씬하다고 볼 수 있을 정도였다. $5.2 \%$ 는 사진 에 짙은 그림자가 졌거나 옷과 배경의 경계를 없애는 디지털 작업을 해서 모델의 체형 식별이 어려웠다.

모델의 인종은 백인이 $64.5 \%$ 로 가장 많았고, 황인 이 $35.5 \%$ 였으며, 흑인은 한 명도 없었다. 백인 모델이 $66.7 \%$ 를 차지하는 닥스 숙녀는 라이센스 브랜드여서 영국 본사의 광고를 그대로 사용할 때도 있고, 국내 용 광고를 촬영할 때에도 영국의 트래디셔널한 이미 지를 연출하기 위해 서양인 모델을 많이 기용하는 것 으로 보인다. 하지만 내셔널 브랜드인 루치아노최는 모두 백인 모델이었고 르베이지는 백인 모델이 $87.9 \%$ 였다. Lee(2009)는 국내 브랜드가 서양 모델을 선호 하는 이유로 세 가지를 언급했는데, 첫째는 국내 브 랜드들이 해외 진출을 고려하여 광고에 글로벌한 이 미지를 표현하려고 하고, 둘째는 많은 기업들이 백인 모델을 쓰면 고급스러운 이미지를 표현할 수 있다고 생각하며, 셋째는 국내 유명 연예인은 모델료가 너무 비싸거나 스캔들로 인해 브랜드 이미지를 훼손할 수 있다는 것이다. 고가 브랜드인 루치아노최, 르베이지 와 중고가 브랜드인 닥스 숙녀는 백인 모델이 많이 등장하는 반면, 중가 브랜드인 지센은 국내 유명 배 우만을 모델로 기용했고, PAT도 한 시즌을 제외하고 모두 국내 유명 배우를 기용했다. 이러한 결과로 미 루어 볼 때, 고가 브랜드들은 백인 모델을 통해 고급 스러운 이미지를 연출하고, 중가 브랜드는 국내 유명 연예인을 통해 친근한 이미지를 전달하면서 주목성 을 높이려는 것으로 판단된다.

신체 표현 범위는 무릎까지가 가장 많았고(34.2\%), 발끝까지(27.1\%)와 엉덩이까지(23.2\%)가 그 다음으로 많았다. 보이는 나이와 신체 표현 범위의 관계를 살 펴보면, 20 대, 30 대로 보이는 모델은 무릎까지가 각각 $44.4 \%, 34.5 \%$ 이고, 발끝까지가 각각 $33.3 \%, 31.0 \%$ 여 서 신체가 많이 드러났다. 하지만 40대로 보이는 모델 은 엉덩이까지 표현된 경우가 가장 많았고(50.0\%), 50 대로 보이는 모델은 가슴까지와 허리까지 표현된 경우가 각각 $33.3 \%$ 로 가장 많았으며, 발목까지나 발 
끝까지 표현된 경우는 전혀 없었다. 즉, 나이가 많아 보일수록 광고에 표현되는 신체 범위가 좁아지는 경 향이 나타났다(Table 3 ).

광고의 컬러 유형과 인물 표현의 선명도는 모델의 특징이 가려지지 않고 얼마나 명확하게 드러나는지 를 보여준다. 광고의 컬러 유형은 컬러가 $83.2 \%$, 흑 백이 $16.8 \%$ 였다. 모델의 보이는 연령과 광고의 컬러 유형 간의 관계를 살펴보면, 보이는 연령이 높을수록 흑백 사진 비중이 높았다. 20대로 보이는 모델이 등 장한 광고는 모두 컬러였고, 30 대로 보이는 모델이
등장한 광고 중 흑백은 $15.5 \%$ 인 반면, 40 대, 50 대로 보이는 모델이 등장한 광고 중 흑백은 각각 $38.5 \%$, $50 \%$ 였다(Table 4). 〈Fig. 7〉, 〈Fig. 8〉처럼 강한 그림 자나 빛이 모델의 일부를 가리거나 디지털 합성을 통 해 배경과 모델의 경계를 모호하게 하여, 인물 표현의 선명도가 낮은 사진 역시 보이는 연령이 높을수록 비 중이 높아졌다. 인물이 선명하게 나타나지 않는 경우 는 20 대, 30 대로 보이는 모델이 등장한 광고에서는 각각 $5.6 \%, 8.3 \%$ 에 불과한 반면, 40 대, 50 대로 보이 는 광고에서는 각각 $23.1 \%, 50.0 \%$ 였다(Table 5).

$<$ Table 3> Range of bodies shown in advertisements by look age

Unit: $n(\%)$

\begin{tabular}{|c|c|c|c|c|c|c|}
\hline \multirow[b]{2}{*}{ Range of bodies } & \multicolumn{5}{|c|}{ Look age } & \multirow{2}{*}{$\begin{array}{c}\text { Total } \\
(N=155)\end{array}$} \\
\hline & $\begin{array}{c}20 \mathrm{~s} \\
(n=36)\end{array}$ & $\begin{array}{c}30 \mathrm{~s} \\
(n=84)\end{array}$ & $\begin{array}{c}40 \mathrm{~s} \\
(n=26)\end{array}$ & $\begin{array}{c}50 \mathrm{~s} \\
(n=6)\end{array}$ & $\begin{array}{l}\text { Indiscernible } \\
\qquad(n=3)\end{array}$ & \\
\hline To the chest & $0(0.0)$ & $4(4.8)$ & $2(7.7)$ & $2(33.3)$ & $0(\quad 0.0)$ & $8(5.2)$ \\
\hline To the waist & $0(0.0)$ & $5(6.0)$ & $2(7.7)$ & $2(33.3)$ & $0(\quad 0.0)$ & $9(5.8)$ \\
\hline To the hip & $4(11.1)$ & $18(21.4)$ & $13(50.0)$ & $1(16.7)$ & $0(\quad 0.0)$ & $36(23.2)$ \\
\hline To the knee & $16(44.4)$ & $29(34.5)$ & $4(15.4)$ & $1(16.7)$ & $3(100.0)$ & $53(34.2)$ \\
\hline To the ankle & $4(11.1)$ & $2(2.4)$ & $1(3.8)$ & $0(0.0)$ & $0(\quad 0.0)$ & $7(4.5)$ \\
\hline To the foot & $12(33.3)$ & $26(31.0)$ & $4(15.4)$ & $0(0.0)$ & $0(\quad 0.0)$ & $42(27.1)$ \\
\hline
\end{tabular}

$p<.001$

$<$ Table $4>$ Color mode of photographs by look age

Unit: $n(\%)$

\begin{tabular}{|c|c|c|c|c|c|c|}
\hline \multirow[b]{2}{*}{ Color mode } & \multicolumn{5}{|c|}{ Look age } & \multirow{2}{*}{$\begin{array}{c}\text { Total } \\
(N=155)\end{array}$} \\
\hline & $\begin{array}{c}20 \mathrm{~s} \\
(n=36)\end{array}$ & $\begin{array}{c}30 \mathrm{~s} \\
(n=84)\end{array}$ & $\begin{array}{c}40 \mathrm{~s} \\
(n=26)\end{array}$ & $\begin{array}{c}50 \mathrm{~s} \\
(n=6)\end{array}$ & $\begin{array}{l}\text { Indiscernible } \\
\qquad(n=3)\end{array}$ & \\
\hline Color & $36(100.0)$ & $71(84.5)$ & $16(61.5)$ & $3(50.0)$ & $3(100.0)$ & $129(83.2)$ \\
\hline$B \& W$ & $0(\quad 0.0)$ & $13(15.5)$ & $10(38.5)$ & $3(50.0)$ & $0(\quad 0.0)$ & $26(16.8)$ \\
\hline
\end{tabular}
$p<.001$

<Table 5> Clarity of models' figures by look age

\begin{tabular}{c|c|c|c|c|c|c}
\hline \multirow{2}{*}{ Clarity } & \multicolumn{7}{|c|}{ Look age } & \multirow{2}{*}{ Total } \\
\cline { 2 - 6 } & $\begin{array}{c}20 \mathrm{~s} \\
(n=36)\end{array}$ & $\begin{array}{c}30 \mathrm{~s} \\
(n=84)\end{array}$ & $\begin{array}{c}40 \mathrm{~s} \\
(n=26)\end{array}$ & $\begin{array}{c}50 \mathrm{~s} \\
(n=6)\end{array}$ & $\begin{array}{c}\text { Indiscernible } \\
(n=3)\end{array}$ & $(N=155)$ \\
\hline Clear & $34(94.4)$ & $77(91.7)$ & $20(76.9)$ & $3(50.0)$ & $1(33.3)$ & $135(87.1)$ \\
\hline Unclear & $2(5.6)$ & $7(8.3)$ & $6(23.1)$ & $3(50.0)$ & $2(66.7)$ & $20(12.9)$ \\
\hline
\end{tabular}

$p<.001$ 


\section{Conclusion}

본 연구는 50 대 여성을 타겟으로 하는 여성복 브 랜드 광고에 나타난 모델 이미지를 분석했다. 이를 통 해서 여성복 브랜드가 중년 여성에게 제시하는 이상 미를 살펴보았으며, 광고에서 여성의 노화를 다루는 방식을 파악했다. 2012년 1월부터 2017년 1월까지 50 대 여성을 메인 또는 서브 타겟으로 하는 닥스 숙 녀, 르베이지, 루치아노최, PAT, 지센의 지면 광고 사 진 155 장을 분석한 결과는 다음과 같다.

첫째, 50 대를 메인 또는 서브 타겟으로 하는 여성 복 브랜드들이 미의 기준을 30 대 이하의 젊고 날씬한 외모에 두고 있으며, 광고를 통해 젊음에 대한 선망 을 강화하고 있다. 조사 브랜드들은 30 대 모델 또는 30 대로 보이는 모델을 가장 선호했다. 심지어 10 대 모 델까지 등장하며, 한 브랜드를 제외하고는 40 대 이상 으로 보이는 모델은 거의 등장하지 않았다. 이는 TV, 신문, 잡지 광고에서 나이든 모델의 등장 빈도가 낮 다는 선행 연구 결과와 일치한다. 선행 연구들은 폭 넓은 연령대를 대상으로 한 매체를 분석했지만 본 연 구가 분석한 광고는 40,50 대 여성을 메인 타겟으로 한다는 점을 감안하면, 패션계에서 나이든 모델을 기 피하는 현상이 매우 심한 것을 알 수 있다. 광고에 타 겟보다 젊은 모델이 등장하는 원인이 중년 모델 수의 부족이라면 젊은 모델을 실제 나이보다 많아 보이도 록 분장을 할 수도 있었을 것이다. 하지만 조사 브랜 드들은 주름, 흰머리, 군살이 없고, 어깨 아래까지 내 려오는 긴 머리를 한 젊은 외모를 그대로 드러나게 했고 40,50 대 모델을 기용할 경우에도 실제 연령보 다 젊어 보이는 모델을 등장시켰다는 점에서 의도적 으로 젊은 이미지를 부각시켰다고 할 수 있다.

둘째, 중년 여성을 타겟으로 하는 의류 광고조차도 중년 모델이 등장할 때 나이든 몸은 가려져야 하는 것으로 표현한다. 모델의 보이는 연령이 높아질수록 흑백 사진의 비중이 높아져서 실제 색상이 나타나지 않고, 강한 빛과 그림자, 디지털 작업으로 얼굴이나 몸매를 가리는 경우가 많아지며, 엉덩이 아래로는 광 고에 잘 나타나지 않는다는 결과가 이를 뒷받침한다. 나이가 들면서 피부 탄력, 피부 톤, 체형에 변화가 오 고 주름이 생길 확률이 높기 때문에 흑백 사진, 강한 명암, 디지털 작업, 엉덩이 부근까지만 나오는 사진은
노화의 흔적을 가려주는 역할을 한다. 광고 실무자가 의도적으로 중년 모델의 몸을 가린 게 아닐지라도, 이러한 현상에는 나이든 여성의 몸은 눈에 두드러지 지 않아야 자연스럽다는 사회적 통념이 드러난다.

셋째, 고가 브랜드일수록 백인 모델 선호 경향이 나 타난다. 중가 브랜드가 국내 유명인 모델 위주의 광고 를 선보이는 것에, 반해 고가 브랜드는 주로 백인 모 델을 기용했다. 르베이지의 경우, 모델의 대다수가 활 발히 사회활동을 하는 일반인이고, 광고에 모델명과 직업을 명시하여 독립적인 여성을 보여주려는 의도 는 참신하지만, 섭외하기 힘든 외국 일반인이 한국 일반인보다 훨씬 많이 등장한다. 만약 글로벌한 이미 지를 전달하기 위해 외국 모델을 기용하는 것이라면, 다양한 인종이 비슷한 비율로 등장해야 할 것이다. 하지만 전체 광고에서 흑인은 전혀 나타나지 않고 고 가 브랜드에서 백인 모델의 비율이 압도적으로 높은 것은 백인을 세련되고 고급스러운 이미지와 연관 짓 는 경향을 드러낸다.

광고 속 모델과 일반 여성의 신체 차이는 젊은 연 령을 타겟으로 하는 광고에서도 빈번히 발생하여 문 제가 되어 왔다. 하지만 젊은 여성을 타겟으로 하는 광 고의 모델은 주로 다양하지 않은 체형 때문에 비판을 받는 반면, 중년 여성을 타겟으로 한 광고는 날씬한 모델 외에도 타겟 소비자보다 몇십 년 젊은 연령의 모델을 등장시켜서 현실에 존재하지 않는 중년 이미 지를 보여준다는 문제가 있다. 타겟보다 젊은 연령의 모델은 소비자의 제품 착용 모습을 예측하기 어렵게 할 뿐만 아니라, 50 대 여성에게 왜곡된 미의 기준을 제공하여 자기 존중감 저하를 유발할 수 있다. 한편, 많지는 않아도 40,50 대 모델이 등장한 광고가 있기는 했지만, 이 경우 시술과 관리를 통해 실제 나이보다 젊어 보이는 연예인을 기용하거나 흑백사진, 강한 빛 과 그림자, 상체 위주의 클로즈업, 디지털 작업 등으 로 모델의 신체 특징이 선명하게 드러나지 않아서 비 판적으로 볼 필요가 있다. 소비자는 주름, 흰머리, 군 살 없는 40,50 대 모델을 보면서 성공적으로 나이 드 는 것은 노화의 흔적이 없는 것이며, 나이든 몸은 가 려야 하는 것으로 인식할 수 있기 때문이다. 선행 연 구들에서 나타나듯이, 광고와 미디어는 중년 여성의 젊음추구 행동에 중요한 정보원이 되며, 큰 영향력을 가지기 때문에 타겟 소비자보다 젊은 모델, 젊어 보 
이는 모델이 주를 이루는 광고는 자연스러운 노화 부 정과 과도한 젊음추구 현상을 일으킬 수 있다. 또한 Lee and Yoh(2016), Kozar(2010, 2012), Kozar and Damhorst(2008)의 연구에서처럼 소비자는 나이든 모델이 나 자신과 유사한 이미지의 모델에 더 긍정적인 태도 를 가질 수 있으므로 중년 여성을 타겟으로 하는 광 고에 관행적으로 젊은 모델을 쓰는 것이 과연 효과적 일지 조사해볼 필요가 있다.

50대 이상의 인구가 많아지고 높은 소비력을 보임 에도 불구하고, 그들을 어떠한 이미지로 표현해야 할 지에 대한 학계와 업계의 고민은 부족해 보인다. 본 연구는 중년 이상의 여성을 대상으로 한 패션 광고에 대한 연구가 부족한 상황에서 연구의 범위를 확장시 켰으며, 중년을 타겟으로 한 여성복 광고조차 어떻게 중년 여성을 소외시키며, 노화에 대한 부정적인 인식 을 심어주는지 분석했다는 점에서 학술적 의의가 있 다. 또한 본 연구는 여성복 매출 하락으로 어려움을 겪고 있는 패션 업계가 새로운 라이프스타일을 추구 하는 50 대 이상의 여성을 공략하기 위해 광고 모델 이미지를 재고할 필요가 있다는 문제제기를 했다는 점에서 실무적 의의를 갖는다. 50대 여성들이 자신의 연령에 적합한 외모를 탐색할 수 있는 경로가 많지 않은 상황에서 중년 여성을 타겟으로 하는 여성복 브 랜드의 광고는 소비자에게 이상적인 외모를 제시하 는 중요한 정보원이다. 따라서 중년 여성을 타겟으로 하는 여성복 브랜드가 어떠한 이미지와 메시지를 전 달하며, 타겟 소비자의 정체성에 부정적인 영향을 주 는 것은 아닌지 지속적으로 관심을 가지고 살펴보아 야 할 것이다.

\section{References}

Advertising Information Center. (2012a, April 1). Lebeige. Retrieved January 20, 2017, from https:// www.adic.or.kr/ad/print/show.cjsp?ukey=502167

Advertising Information Center. (2012b, September 1). Lebeige. Retrieved January 20, 2017, from https://www.adic.or.kr/ad/print/show.cjsp?ukey=7 98788

Advertising Information Center. (2013a, March 1). PAT. Retrieved January 20, 2017, from https:// www.adic.or.kr/ad/print/show.cjsp?ukey=903899 Advertising Information Center. (2013b, July 1). Zishen. Retrieved January 20, 2017, from https://www.adic. or.kr/ad/print/show.cjsp?ukey $=938768$

Advertising Information Center. (2013c, March 1). Lebeige. Retrieved January 20, 2017, from https:// www.adic.or.kr/ad/print/show.cjsp?ukey $=903876$

Advertising Information Center. (2014, September 1). Luciano Choi. Retrieved January 20, 2017, from https://www.adic.or.kr/ad/print/show.cjsp?ukey=1 070017

Advertising Information Center. (2015, October 1). Daks. Retrieved January 20, 2017, from https://www.adic. or.kr/ad/print/show.cjsp?ukey=1434181

Advertising Information Center. (2016, November 1). Daks. Retrieved January 20, 2017, from https://www. adic.or.kr/ad/print/show.cjsp?ukey $=1574337$

Advertising Information Center. (2017, January 1). Heart for eye. Retrieved January 20, 2017, from https://www.adic.or.kr/ad/print/show.cjsp?ukey=1 596532

Apparelnews. (2014). 한국패션브랜드 연감 2014/2015 [Korea fashion brand annual 2014/2015]. Seoul: Apprarelnews.

Byun, M. Y. (2011). Development of casual ware design for new middle-aged women. Unpublished doctoral dissertation, Ewha Womans University, Seoul, Korea.

Carrigan, M., \& Szmigin, I. (1999). The representation of older people in advertisements. Journal of the Market Research Society, 41(3), 311-326.

Choi, J.-W. (2011). Study on pursuing clothing image and clothing purchase activity according to ego identity and subjective age of new middle-aged women. Unpublished doctoral dissertation, Sookmyung Women's University, Seoul, Korea.

Clarke, L. H., \& Griffin, M. (2008). Visible and invisible ageing: Beauty work as a response to ageism. Ageing \& Society, 28(5), 653-674. doi:10.1017/ S0144686X07007003

Cohen, P. (2013). In our prime: The fascinating his- 
tory and promising future of middle age. New York: Scribner.

Coupland, J. (2009). Time, the body and the reversibility of ageing: Commodifying the decade. Ageing \& Society, 29(6), 953-976. doi:10.1017/S0144686 X09008794

De Perthuis, K. (2008). Beyond perfection: The fashion model in the age of digital manipulation. In E. Shinkle (Ed.), Fashion as photograph: Viewing and reviewing images of fashion (pp. 168-181). London: I. B. Tauris.

Firstviewkorea. (2012a, March). Fashion index of behavior and attitude, PFIN consumer survey. Firstviewkorea, Retrieved February 5, 2015, from http:// www.firstviewkorea.com/Market/Fiba.aspx?SchCa teCode $1=\mathrm{SS} 024$

Firstviewkorea. (2012b, November). Fashion index of behavior and attitude, PFIN consumer survey. Firstviewkorea, Retrieved February 5, 2015, from http://www.firstviewkorea.com/Market/Fiba.aspx? SchCateCode $1=$ SS027

Firstviewkorea. (2013a, April). Fashion index of behavior and attitude, PFIN consumer survey report. Firstviewkorea, Retrieved February 5, 2015, from http://www.firstviewkorea.com/Market/Fiba.aspx? SchCateCode $1=$ SS028

Firstviewkorea. (2013b, December). Fashion index of behavior and attitude, PFIN consumer survey report. Firstviewkorea, Retrieved February 5, 2015, from http://www.firstviewkorea.com/Market/Fiba. aspx?SchCateCode $1=$ SS029

Firstviewkorea. (2014a, June). Fashion index of behavior and attitude, PFIN consumer survey report. Firstviewkorea, Retrieved February 5, 2015, from http://www.firstviewkorea.com/Market/Fiba.aspx? SchCateCode $1=$ SS030

Firstviewkorea. (2014b, November). Fashion index of behavior and attitude, PFIN consumer survey report. Firstviewkorea, Retrieved February 5, 2015, from http://www.firstviewkorea.com/Market/Fiba. aspx?SchCateCode $1=\mathrm{SS} 031$
Firstviewkorea. (2015a, June). Fashion index of behavior and attitude, PFIN consumer survey report. Firstviewkorea, Retrieved December 16, 2016, from http://www.firstviewkorea.com/Market/Fiba. aspx?SchCateCode $1=\mathrm{SS} 032$

Firstviewkorea. (2015b, November). Fashion index of behavior and attitude, PFIN consumer survey report. Firstviewkorea, Retrieved December 16, 2016, from http://www.firstviewkorea.com/Market/Fiba. aspx?SchCateCode $1=$ SS033

Firstviewkorea. (2016a, June). Fashion index of behavior and attitude, PFIN consumer survey report. Firstviewkorea, Retrieved December 16, 2016, from http://www.firstviewkorea.com/Market/Fiba. aspx?SchCateCode1 $=$ SS034

Firstviewkorea. (2016b, November). Fashion index of behavior and attitude, PFIN consumer survey report. Firstviewkorea, Retrieved December 16, 2016, from http://www.firstviewkorea.com/Market/ Fiba.aspx?SchCateCode1 $=$ SS035

Greco, A. J. (1988). Representation of the elderly in advertising: Crisis or inconsequence?. Journal of Services Marketing, 2(3), 27-34. doi:10.1108/eb0 24731

Halls, Z. (2000). Mrs Exeter: The rise and fall of the older woman. Costume, 34(1), 105-112. doi:10.1179/ cos.2000.34.1.105

Hollander, A. (1993). Seeing through clothes. Berkely: University of California Press.

Hong, K. H. (2010). The influence of middle aged women's TV media involvement on difference age, youth-pursuing clothing behaviors and fashion leadership. Fashion \& Textile Research Journal, 12(3), 310-317. doi:10.5805/KSCI.2010. 12.3.310

Im, M. J. (2016). Semiotic analysis on aged female models' images in fashion advertisements: Focusing on global fashion brands. Journal of Basic Design \& Art, 17(4), 383-400.

Jang, E. J., \& Yoo, H. S. (2011). Cognitive ages and body images of Korean adults in their 40s and 
50s. Fashion \& Textile Research Journal, 13(5), 769-777. doi:10.5805/KSCI.2011.13.5.769

Jun, J. H., \& Rhee, Y. S. (2016). The relation of youthpursuing, media appearance information interest, and media contact response of middle-aged women: Influence of chronological age and cognitive age. Journal of the Korean Society of Clothing and Textiles, 40(4), 631-640. doi:10.5850/JKSCT.2016. 40.4.631

Kim, J. S., \& Lee, S. J. (2008). A study on the spending behaviors, related to the cognitive age of the female consumers in the elderly generation and different types of their lifestyles (Part1). Journal of the Korean Society of Clothing and Textiles, 32(10), 1535-1547. doi:10.5850/JKSCT.2008.32.10. 1535

Kim, M. (2010). The roles and images of the elderly in advertising. Journalism \& Communication, 14 (1), 3-40.

Kim, M. H., \& Won, Y. H. (1999). Analysis on image of the elderly in newspaper advertisements: The establishments for new image of the elderly. Journal of the Korea Gerontological Society, 19 (2), 193-214.

Kim, M.-A. (2001). Perceptions of advertising practitioners on the elderly in advertising. The Korean Journal of Advertising, 12(5), 57-70.

Kim, M.-J., \& Moon, C.-S. (2016). A comparison of consumption expenditure patterns and their determinants of baby boomer households and elderly households. Consumption Culture Study, 19(3), 31-54.

Kim, R., Jeon, M., Lee, H., Lee, J., Kim, S., \& Choi, J. (2014). 트렌드 코리아 2015 [Trend Korea 2015]. Seoul: Miraeuichang.

Kim, S. Y. (2015). Application type and meaning of senior chic in contemporary fashion. Korea Science \& Art Forum, 20, 103-117. doi:10.17548/ksaf. 2015.06.20.103

Ko, K. A. (2016). 잡지광고에 나타난 액티브시니어 의 이미지 변화 연구 [Study on the change of active senior image in magazine advertising]. Unpublished master's thesis, Kyung Hee University, Seoul, Korea.

Kozar, J. M. (2010). Women's responses to fashion media images: A study of female consumers aged 30-59. International Journal of Consumer Studies, 34(3), 272-278. doi:10.1111/j.1470-6431.2009.00854.x

Kozar, J. M. (2012). Effects of model age on adult female consumer's purchase intentions and attitudes for an age-specific product, clothing. International Journal of Marketing Studies, 4(2), 22-29. doi:10.5539/ijms.v4n2p22

Kozar, J. M., \& Damhorst, M. L. (2008). Older women's responses to current fashion models. Journal of Fashion Marketing and Management: An International Journal, 12(3), 338-350. doi:10.1108/ 13612020810889290

Kwon, G.-Y., \& Helvenston, S. I. (2006). The study of ideal body images based on the product types in fashion magazine advertisement. Journal of the Korean Society of Clothing and Textiles, 30 (12), 1672-1682.

Lee, E., \& Yoh, E. (2016). Research on female consumer responses according to advertising model types of a senior apparel brand. The Research Journal of the Costume Culture, 24(1), 93-106. doi:10.7741/rjec.2016.24.1.093

Lee, J. M. (2013, September 27). 다이나믹 시니어! 골든 마켓으로 [Dynamic seniors! To the golden market]. Fashionbiz, Retrieved May 2, 2017, from http://www.fashionbiz.co.kr/article/view.asp? idx $=135244$

Lee, S. J. (2009). Study of the changing role of models in the fashion industry: Analysis of fashion magazines from 1998 to 2007. Unpublished master's thesis. Hanyang University, Seoul, Korea.

Lee, S., \& Chun, J. (2015). The upper body type classification of middle-aged and elderly Korean women. The Research Journal of the Costume Culture, 23(3), 512-522. doi:10.7741/rjcc.2015.23.3.512

Lee, W. H., \& Hong, S. H. (2016, November). 블루 
오션 '골든 레이디'를 잡아라! [Catch the blue ocean 'golden ladies!']. Fashionbiz, 355, 54-62.

Lee, Y.-A. (2011). Study on the real image and the recognized image of middle-aged women: Comparison of the ages. Journal of Korean Traditional Costume, 14(3), 5-16.

Lewis, D. M., \& Cachelin, F. M. (2001). Body image, body dissatisfaction, and eating attitudes in midlife and elderly women. Eating Disorders, 9(1), 29-39. doi:10.1080/106402601300187713

Mears, A. (2011). Pricing beauty: The making of a fashion model. Berkeley: University of California Press.

Park, H. Y. (2009). A Study of the roles and characteristics of elderly models appearing in television commercials. Unpublished master's thesis, Yonsei University, Seoul, Korea.

Raisborough, J., Barnes, M., Henwood, F., \& Ward, L. (2014). Stretching middle age: The lessons and labours of active ageing in the makeover show. Media, Culture \& Society, 36(8), 1069-1083. doi:10.1177/0163443714544997

Simcock, P., \& Sudbury, L. (2006). The invisible majority? Older models in UK television advertising. International Journal of Advertising, 25(1), 87-106. doi:10.1080/02650487.2006.11072953

Song, Y.-J. (2012). Breaking age barriers: Adornment of middle-aged and elderly women. Journal of Social Research, 13(2), 83-111.
Statistics Korea. (2017). Population projection for Korea. Retrieved May 3, 2017 from http://kosis .kr/statHtml/statHtml.do?orgId=101\&tblId=DT_1 BPA001\&conn_path=I2

Swayne, L. E., \& Greco, A. J. (1987). The portrayal of older Americans in television commercials. Journal of Advertising, 16(1), 47-54. doi:10.1080/ 00913367.1987 .10673060

Synnott, A. (1993). The body social: Symbolism, self, and society. New York: Routledge.

Thesander, M. (1997). The feminine ideal. London: Reaktion Books.

Twigg, J. (2010). How does Vogue negotiate age?: Fashion, the body, and the older woman. Fashion Theory, 14(4), 471-490. doi:10.2752/175174110X 12792058833898

Twigg, J. (2012). Fashion and age: The role of women's magazines in the constitution of aged identities. In V. Ylänne (Ed.), Representing ageing: Images and identities (pp. 132-146). Basingstoke: Palgrave Macmillan.

Ursic, A. C., Ursic, M. L., \& Ursic, V. L. (1986). A longitudinal study of the use of the elderly in magazine advertising. Journal of Consumer Research, 13(1), 131-133. doi:10.1086/209054

Yoo, H. A. (2014). Qualitative research of middleaged women's ideal body seeking behavior. Unpublished master's thesis, Sungkyunkwan University, Seoul, Korea. 